\title{
Development of a Synergistic Approach to Study Irradiated Materials Using Coupled Experiments and Simulation - FY2018 final poster
}

Cynthia A Adkins, Assel Aitkaliyeva, Michael Tonks, Daniel M Wachs, Jacob Hirschhorn

\section{August 2018}

The INL is a U.S. Department of Energy National Laboratory operated by Battelle Energy Alliance

Idaho National Laboratory 


\section{Development of a Synergistic Approach to Study Irradiated Materials Using Coupled Experiments and Simulation - FY2018 final poster}

Cynthia A Adkins, Assel Aitkaliyeva, Michael Tonks, Daniel M Wachs, Jacob Hirschhorn

August 2018

Idaho National Laboratory Idaho Falls, Idaho 83415

http://www.inl.gov

Prepared for the U.S. Department of Energy Office of Nuclear Energy Under DOE Idaho Operations Office

Contract DE-AC07-05ID14517 


\title{
Development of a Synergistic Approach to Study Irradiated Materials Using Coupled Experiments and Simulation
}

\author{
Assel Aitkaliyeva ${ }^{1,2}$, Cynthia Adkins ${ }^{1}$, Daniel Wachs ${ }^{1}$, Michael Tonks ${ }^{2}$, Jacob Hirschhorn ${ }^{2}$ \\ ${ }^{1}$ Idaho National Laboratory, ${ }^{2}$ University of Florida
}

Objective

1) develop experimental procedures to obtain the specific pre- and post-irradiation characterization data required for validation and uncertainty quantification of MARMOT models

2) understand the evolution of microstructure under transient irradiation conditions and its impact on properties for use with TREAT.

3) demonstrate the value of a coupled experimental and simulation approach on understanding critical thermal properties in a material of broad interest (the U-Pu-Zr system and its binaries)

\section{Characterization Results}

- Microstructure was observed with SEM, TEM and crystal structure determined with SAED patterns (as-cast vs. anneal at TREAT temperature)

- Phase transition temperatures and energies were measured

- Thermal conductivity was measured
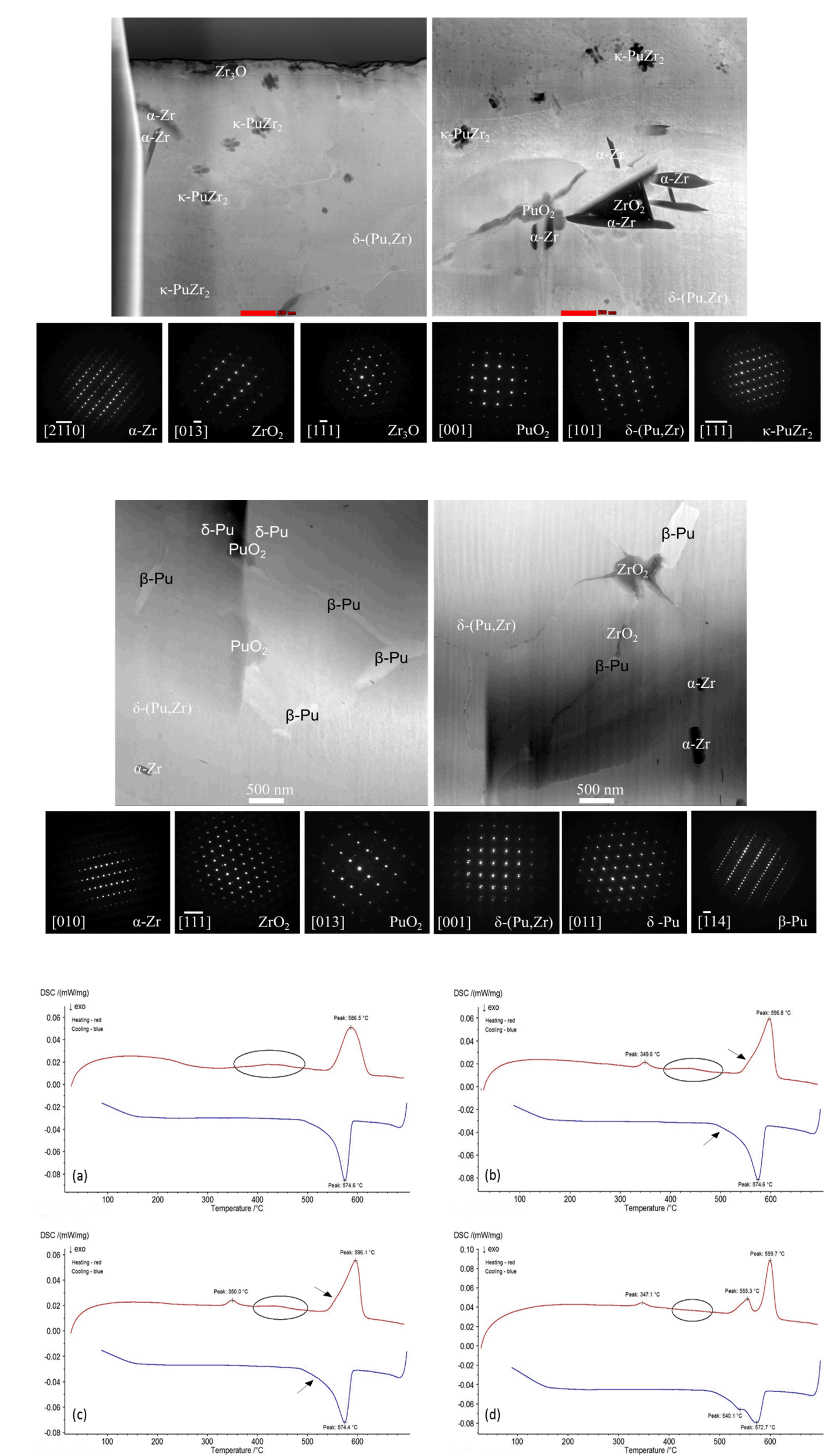

DSC signal vs. Temperature $\left({ }^{\circ} \mathrm{C}\right)$ for Pu-10Zr upon heating and cooling
Technical Challenges

- New irradiation hardware design was needed to enable irradiation in TREAT MARCH vehicle

- TREAT irradiation scheduled for year 2 of this project was delayed

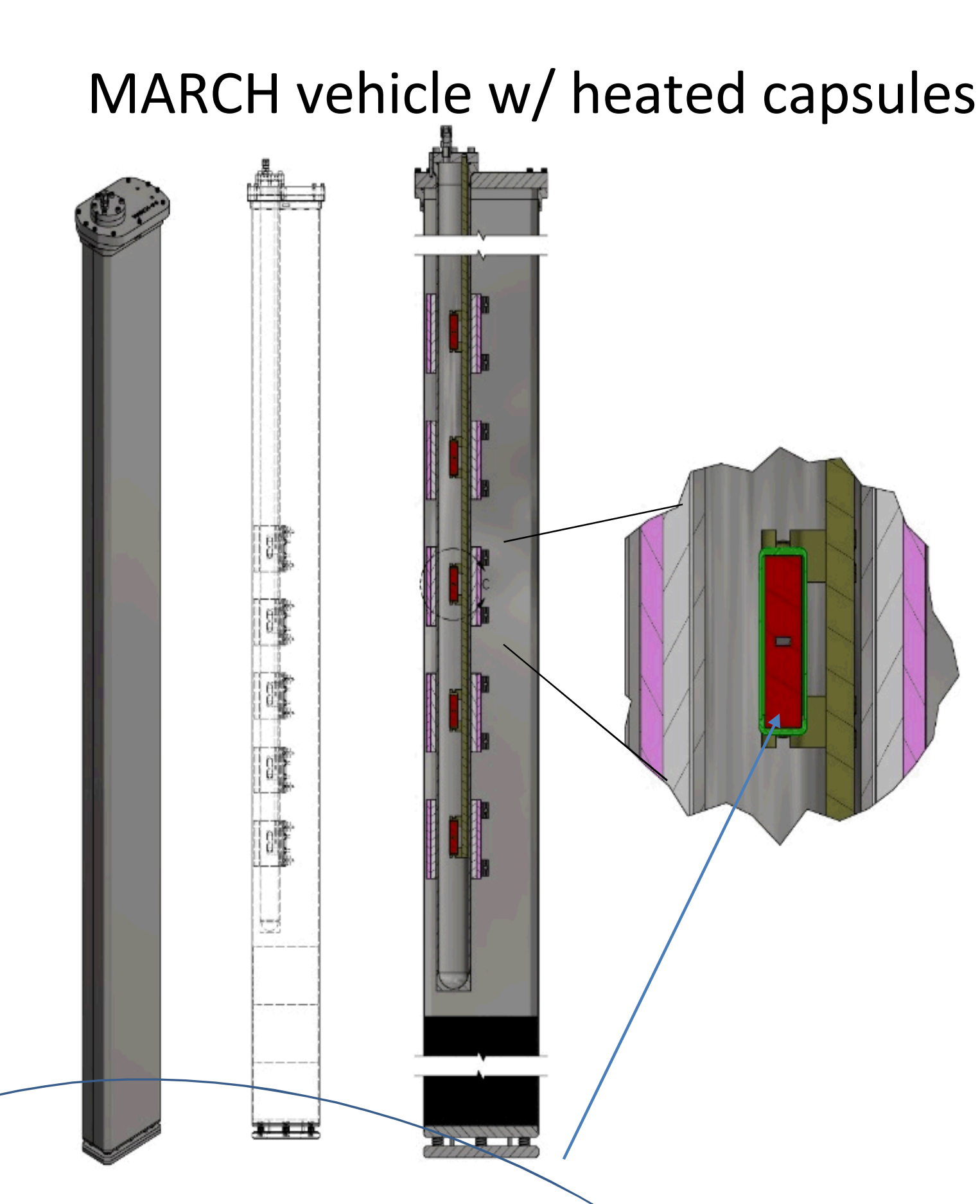

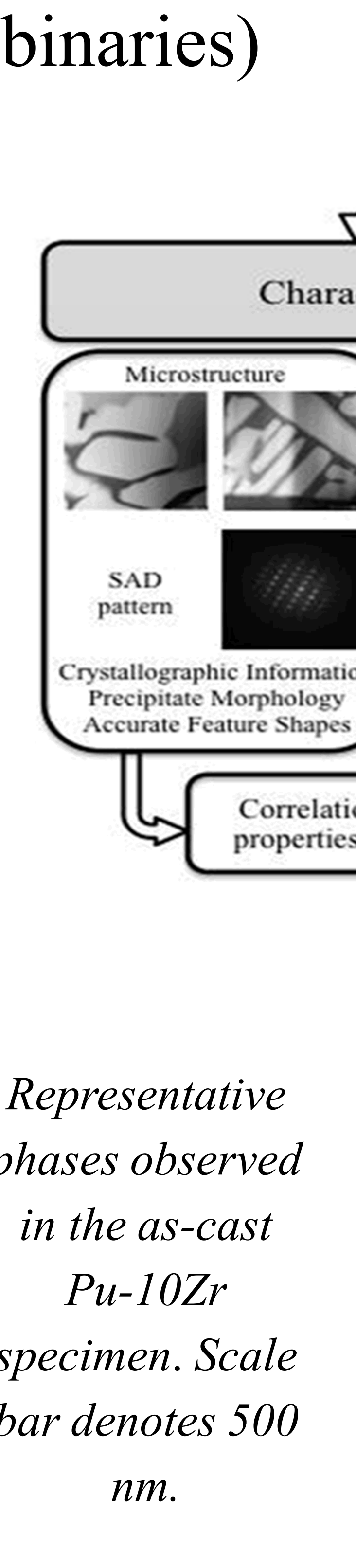

Representative phases observed in the annealed $\mathrm{Pu}-10 \mathrm{Zr}$ specimen. Scale bar denotes 500 $n m$.

(a) 1st thermal cycle of as-cast material (b) 2nd thermal cycle of as-cast material (c) 3rd thermal cycle of as-cast material (d) $1 s t$ thermal cycle of annealed material
Technical Approach
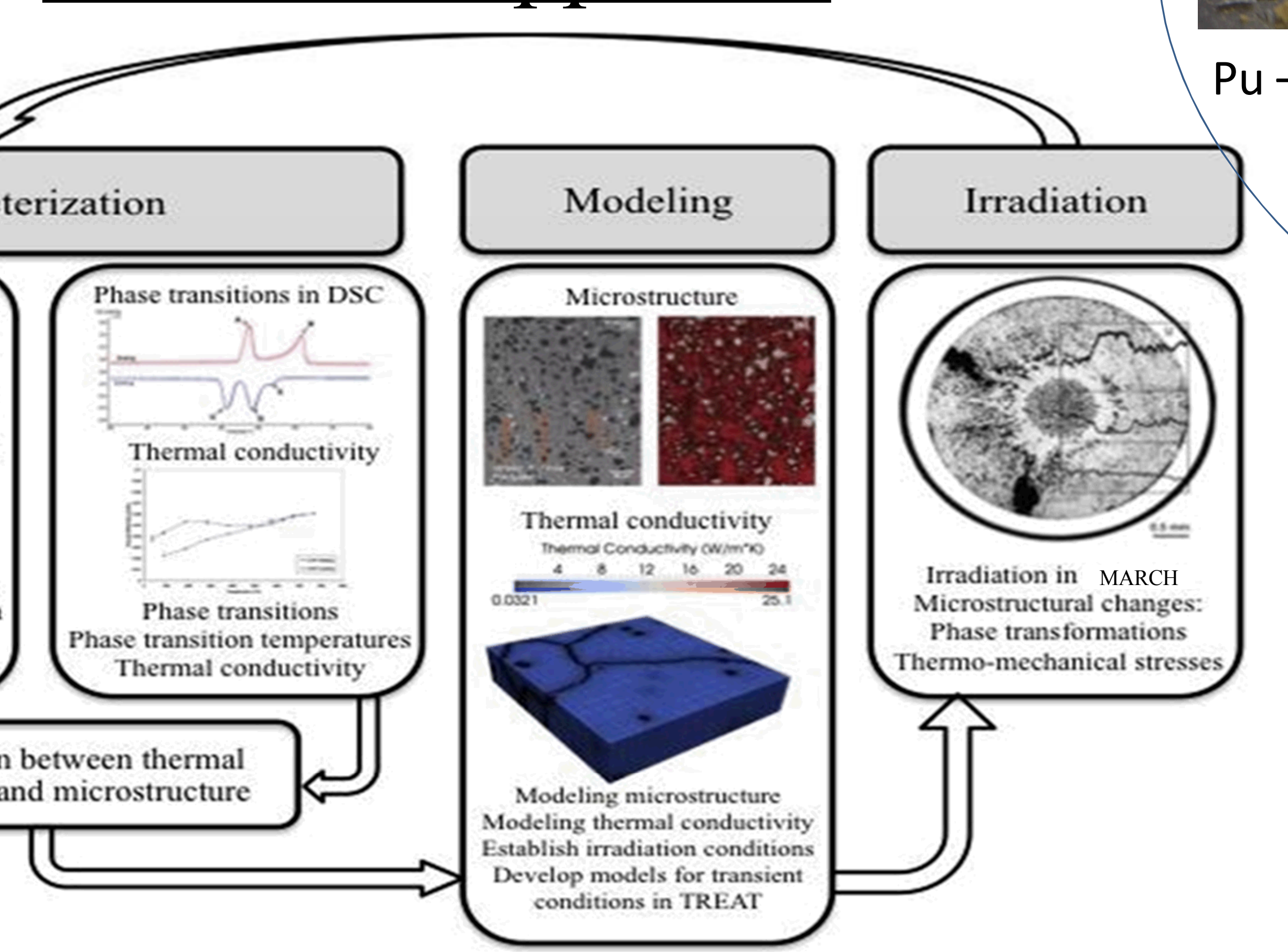

\section{Modeling Results}

- Uses measured and published single phase transition temps to predict microstructure evolution with phase-field model


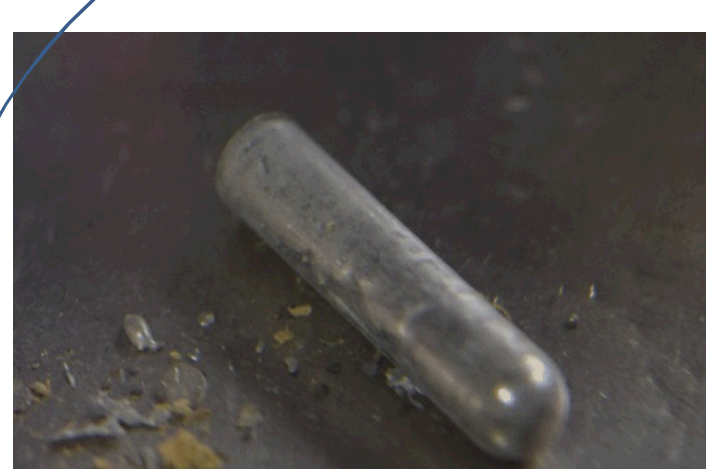

$\mathrm{Pu}-30 w t \% \mathrm{Zr}$

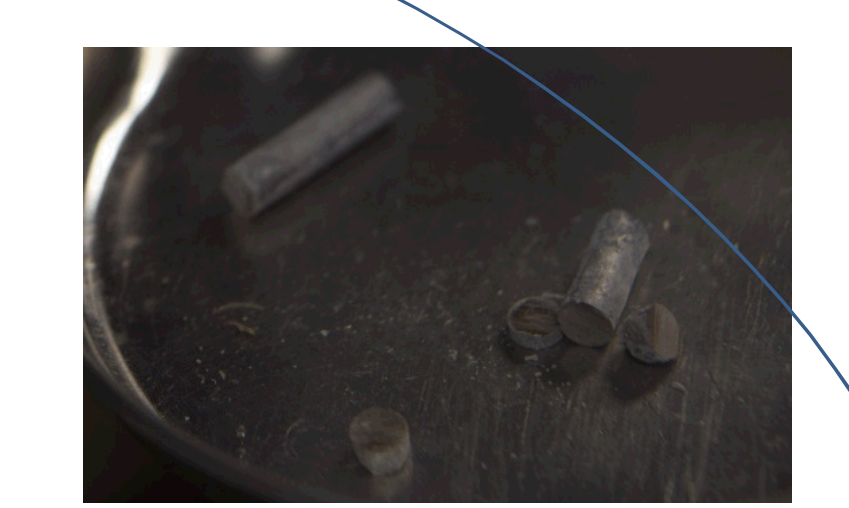

$\mathrm{U}-20 \mathrm{wt} \% \mathrm{Pu}-10 \mathrm{wt} \% \mathrm{Zr}$

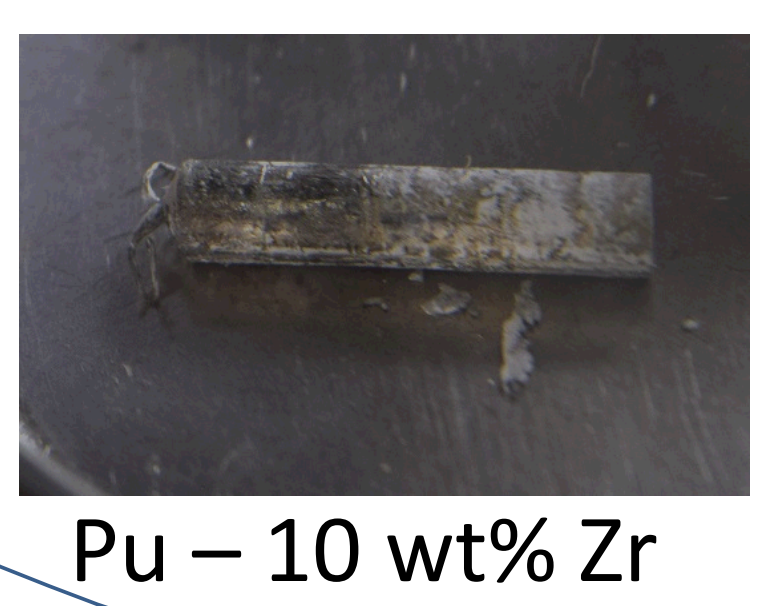

$\underline{\text { Publications }}$

- Development and Verification of a Phase Field Model for the Equilibrium Thermodynamics of U-Pu-Zr, Hirschhorn, Tonks, Aitkaliyeva, Adkins - in review

- The evolution of the microstructure and thermal properties of $\mathrm{Pu}-10 \mathrm{Zr}$ fuels with temperature, Aitkaliyeva, Adkins, Hirschhorn, McKinney, Tonks - in draft

- Thermal Conductivity of Pu-Zr alloys, Adkins, Aitkaliyeva, Hirschhorn, Tonks - in draft

- 9+ presentations in conference proceedings

\section{Harvest Strategy Result}

The work completed for this LDRD has attracted interest from the NTRD program in FY 2019 to develop a new work package for separate effects testing 